\title{
The psychological impact of inflammatory bowel disease as regards anxiety and depression: a single-center study
}

\author{
Safaa Askar ${ }^{1}$, Mohamed Amin Sakr ${ }^{1}$, Waleed Hamed Abd Alaty ${ }^{1}$, Ola M. Aufa ${ }^{2,3^{*}}$ (D), Shimaa Y. Kamel', \\ Mohamed Eltabbakh¹, Ahmed F. Sherief ${ }^{1}$, Mostafa A. A. Shamkh ${ }^{1}$ and Heba Rashad ${ }^{1}$
}

\begin{abstract}
Background: Patients suffering from inflammatory bowel disease (IBD) are not systematically screened against depression as well as anxiety, although there are high prevalence and adverse influence on the quality of life. The aim of this work was to determine generalized anxiety disorder and major depressive disorder prevalence in patients with $\mathrm{IBD}$, and the secondary objective was to identify patient properties linked to higher psychiatric disorder rates.

Results: We determined anxiety and depression prevalence in 105 IBD patients ( 82 having ulcerative colitis and 23 suffering from Crohn's disease) through a psychiatric interview using the Arabic version of Structured Clinical Interview for DSM IV Axis I diagnosis (SCID I), in addition to severity assessment of major depressive disorder and generalized anxiety disorder using the Hamilton Depression Scale (HAM-D) and the Hamilton Anxiety Scale (HAM-A), respectively. Patient data, disease characteristics, and drug information were also gathered. We found a high depression prevalence of $56.2 \%(n=59)$, followed by $37.1 \%(n=39)$, with no significant association between IBD severity and anxiety and depression severity.
\end{abstract}

Conclusion: Depression and/or anxiety affected a large number of IBD patients. Such psychiatric disorders'frequency would warrant detection as well as referral to psychiatric treatment.

Keywords: IBD, Depression, Anxiety

\section{Background}

Inflammatory bowel disease (IBD), involving ulcerative colitis and Crohn's disease, represents one of the debilitating chronic gastrointestinal diseases that has a significant adverse influence on the physical, psychological, family, and social dimensions of patients [1].

The prevalence of depression and anxiety in patients with chronic diseases in the general population is high, but they continue to receive insufficient treatment despite their significant adverse influences on the health and life quality of patients [2]. Depressive disorders are

\footnotetext{
*Correspondence: olaaufa@gmail.com

${ }^{3}$ Department of Psychiatry, Faculty of Medicine, Ain Shams University, No. 38 Abbaseya st., Cairo 11517, Egypt

Full list of author information is available at the end of the article
}

linked to dysfunction in addition to morbidity and mortality increase in people having chronic diseases [3].

The psychological effects of IBD and its drug treatment occur in several IBD patients. In particular, anxiety can hold a remarkable influence on the life quality, comprising workability as well as family life [4].

Population-based research respectively found that the lifetime prevalence of anxiety and depression in IBD patients was 24.4 to $31.9 \%$ and 21.8 to $22.5 \%$, respectively [5]. In a recent systematic review, the combined prevalence of anxiety and depression in IBD patients were $19.1 \%$ and $21.2 \%$, respectively [6].

The mutual association between IBD as well as mental health issues has already been described and can be explained using the "brain-gut" axis. Such axis presents 
that intestinal inflammation existence can adversely affect mood, and conversely, anxiety and/or depression can exacerbate intestinal inflammation and mediate IBD relapse $[7,8]$.

Although most studies have only found statistical associations and cannot demonstrate a clear causeeffect relationship, the recent research suggests two-way interactions between depression and gastrointestinal inflammation. Currently, CD and UC are considered multifactorial diseases with complex pathogenesis that involves an abnormal immune response with a chronic pro-inflammatory state and a cytokine imbalance with a predominance of pro-inflammatory cytokines, including autoimmune phenomena and changes in anti-inflammatory pathways, interactions with the gut microbiota, and impaired brain-gut axis. The mechanisms that lead to depression development overlap with those that are central to IBD pathogenesis [9].

Treating depression and anxiety can enhance longterm results. Therefore, patients' identification at higher anxiety and depression risk is extremely vital to be treated appropriately.

IBD and mental health concerns impose a huge burden on their sufferers physically, mentally, and financially. To our knowledge, few studies have focused on the comorbidity of anxiety/depression in Egyptian IBD patients. Thus, the present study aimed to determine the prevalence of symptoms of anxiety/depression in the Egyptian IBD population and comprehensively analyze the impact of symptoms of anxiety/depression on IBD-related features.

The main objective of the current work was to determine generalized anxiety disorder and major depressive disorder prevalence in patients with IBD, who attended a gastroenterology outpatient clinic. The secondary objective was to identify patient properties linked to higher psychiatric disorder rates.

\section{Methods}

\section{Study participants and sample size calculation} Study setting

IBD Study Group Clinic, Tropical Medicine Department, Ain Shams University Hospitals.

\section{Study period}

(3 months) From October 2020 till the end of December 2020.

\section{Sample size}

Using Epi Info 7 program for sample size calculation and according to previous literature, we assume a $25 \%$ prevalence of depression or anxiety among IBD patients. Setting margin of error at $10 \%$ and confidence level at $95 \%$, the sample size of 75 patients will be needed at mimimum.

Our study comprised 105 patients with IBD and fulfilled the inclusion and exclusion criteria, presented at the IBD Study Group Clinic, Department of Tropical Medicine, Ain Shams University Hospitals. IBD was diagnosed using conventional criteria of the disease. All IBD patients met the standard criteria for $\mathrm{CD}$ or $\mathrm{UC}$, which is based on a combination of clinical, biochemical, stool, endoscopic, cross-sectional imaging, and histological investigations. The diagnosis of $\mathrm{CD}$ and $\mathrm{UC}$ was based on the third European Evidence-based Consensus on Diagnosis and Management of Crohn's disease and ulcerative colitis [10].

\section{Exclusion criteria}

1. Disease duration of more than 3 years

2. Patients with a past history of other psychiatric disorders

3. Some serious chronic conditions, such as chronic heart failure and chronic obstructive pulmonary disease, as well as other immunological disorders and cancer

4. Pregnancy

All patients with IBD who visited the outpatient clinic and fulfilled the criteria were interviewed by a consultant psychiatrist.

\section{Study design}

This clinical study exhibited observational as well as cross-sectional features. IBD patients were subjected to provide demographic and social data. Through validated clinical questionnaires as well as scoring systems, depression and anxiety assessments were accomplished. Our study got approval from the Medical Ethics Review Committee of the Faculty of Medicine at Ain Shams University, Egypt.

\section{Study procedures}

All patients visiting the clinic and fulfilled the criteria have been evaluated by a consultant psychiatrist using Structured Clinical Interview for DSM IV Axis I Diagnosis (SCID I) [11] using the Arabic version [12] for the current existence of major depressive disorder or generalized anxiety disorder. A severity assessment of depression and anxiety in patients was carried out utilizing the Hamilton Depression Scale (HAM-D) [13] and the Hamilton Anxiety Scale (HAM-A) [14]. The severity of IBD was assessed for all patients using Crohn's Disease Activity Index (CDAI) for Crohn's disease and Mayo score for ulcerative colitis. 
SCID I [11] is a structured interview conducted by a clinician to be used in undergoing psychopathological evaluation of psychiatric patients or non-patient subjects. SCID I development was to afford coverage for psychiatric diagnoses following DSM IV and was rationally designed to exhibit more efficiency and be utilized easily over other existing tools. Therefore, it takes less time to train and manage, reaching about $30 \mathrm{~min}$ to be applied.

The HAM-D [13] scale is possibly the most widely used rating scale for depressive symptoms. Despite the original scale consisted of 21 items, Hamilton proposed that only the first 17 items were rated. The other four items were rare (for example, depersonalization), or other aspects of the condition were described rather than severity (for example, daily variation). So, we applied the 17 -item scale. For HAM-D17, a score of 0 to 7 is generally believed to be within the normal range (or in clinical remission), while a score of 20 or more (indicating at least a moderate degree of severity) is generally accepted for entering a clinical trial. It takes about $30 \mathrm{~min}$ to apply the HAM-D.

The HAM-A [14] scale was one of the first rating scales established for measuring anxiety symptoms' severity and is commonly utilized in clinical and research settings to date. This scale comprises 14 items, each represented by a set of symptoms, and can measure mental anxiety (excitement and mental anguish) and somatic anxiety (physical symptoms associated with anxiety).

Crohn's Disease Activity Index (CDAI) is the gold standard to measure disease activity for Crohn's disease (CD) research. The CDAI is computed using laboratory data, physical exam findings, and self-reported CD symptoms for each of the prior 7 days. Scores $<150$ define remission, 150-219 mild activity, 220-450 moderate activity, and $>450$ severe activity [15].

The most commonly used index for studies of the efficacy of ulcerative colitis (UC) therapy is the 12-point Mayo score. This composite index includes patientreported estimates of stool frequency and bleeding, endoscopic assessment of mucosal inflammation, and the physician's global assessment of disease activity. The 6-point Mayo score uses only the number of bowel movements above average and the bleeding components of the full Mayo score. Scores above 1.5 are indicative of active disease [16].

\section{Statistical analysis}

The obtained data were processed, coded, tabulated, and entered in a PC with the Statistical Package for Social Sciences (SPSS 25). After data presentation, the appropriate analysis was performed based on the data type collected for each parameter.

\section{Descriptive statistics}

1. Mean, standard deviation $( \pm S D)$, and range for parametric numerical data, while median and interquartile range $(I Q R)$ for non-parametric numerical data

2. Frequency and percentage of non-numerical data

\section{Analytical statistics}

1. The Student $t$-test was utilized for statistical assessment of the significance difference between means of two study groups.

2. The chi-square test was employed for examining the correlation between two qualitative variables.

3. Fisher's exact test was deployed for examining the association between two qualitative variables if the anticipated count is $<5$ in more than $20 \%$ of cells.

4. Correlation analysis (Pearson's method) was utilized for assessing the association strength between two quantitative variables. The correlation coefficient " $r$ " defines the strength (magnitude) as well as direction (positive or negative) of a linear relationship between two variables.

- $r=0-0.19$ is considered as a very weak correlation

- $r=0.2-0.39$ as weak correlation

- $r=0.40-0.59$ as moderate correlation

- $r=0.6-0.79$ as strong correlation

- $r=0.8-1$ as very strong correlation $p$-value: level of significance $-p>0.05:$ non-significant (NS) $p<$ 0.05: sig-

nificant $(S)-p<0.01$ : highly significant $(H S)$

\section{Results}

\section{Features of the patient's population}

The total number of patients with IBD involved was 105, females (54\%) and males (46\%) having 33.2 years a mean age, single (approximately 51\%), and urban residents (73.3\%). Of 105 patients with IBD, 82 exhibited UC and 23 held Crohn's disease. For evaluating IBD activity in our patients, we calculated the Mayo score and Crohn's Disease Activity Index (CDAI), providing a mean Mayo score of approximately 8.4 and a mean CDAI of about 238.4 as shown in Table 1.

Prevalence of major depressive disorder and generalized anxiety disorder in patients with IBD

We revealed that 59 patients (56.2\%) had major depressive disorder alone (20 patients versus $19.1 \%$ of all patients) or 
Table 1 Characteristics of the patient population

\begin{tabular}{|c|c|c|c|c|c|}
\hline & & Mean/N & $S D / \%$ & Median (IQR) & Range \\
\hline Age & & 33.2 & 11.0 & $32(25-40)$ & $(12-76)$ \\
\hline \multirow[t]{2}{*}{ Sex } & Female & 56 & $53.3 \%$ & & \\
\hline & Male & 49 & $46.7 \%$ & & \\
\hline \multirow[t]{2}{*}{ Residency } & Urban & 77 & $73.3 \%$ & & \\
\hline & Rural & 28 & $26.7 \%$ & & \\
\hline \multirow[t]{3}{*}{ Marital status } & Single & 53 & $50.5 \%$ & & \\
\hline & Married & 48 & $45.7 \%$ & & \\
\hline & Divorced & 4 & $3.8 \%$ & & \\
\hline \multirow[t]{2}{*}{ IBD } & UC & 82 & $78.1 \%$ & & \\
\hline & Crohn's & 23 & $21.9 \%$ & & \\
\hline Mayo score UC $(N=82)$ & & 8.4 & 2.6 & $8(7-10)$ & $(4-12)$ \\
\hline $\operatorname{CDAI}(N=23)$ & & 238.84 & 62.29 & $251(180-275)$ & (159-413) \\
\hline
\end{tabular}

IQR interquartile range; SD standard deviation; CDAI Crohn's Disease Activity Index; Mayo score is an index for the severity of ulcerative colitis

both depression and anxiety (39 patients, 37.1\%). HAM-D ranged between 8 and 29 with a mean of 16.4, while HAM-A ranged between 10 and 50 with a mean of 19.5 as shown in Table 2 . We noticed that all anxiety patients $(39$ patients, 37.1\%) had depression, while 20 patients (19.1\% of all patients) had only depression as shown in Table 3.

\section{Comparison between the group of those with depression} and those without as regards socio-demographic data and disease characteristics

The study revealed a significant age difference between the group of those with depression and those without depression since the group with depression was older than the group without depression $(p$-value $=0.034)$. No significant changes were reported regarding the two groups regarding gender, residence, and marital status. Besides, no significant changes in depression prevalence were present between the two IBD types as seen in Table 4 .

\section{Comparison between the group of those with anxiety} and those without as regards socio-demographic data and characteristics of the disease

No significant changes have been found between the group of patients with and without anxiety regarding age, gender, place of residence, and marital status. Besides, we stated no significant differences between ulcerative colitis as well as Crohn's disease in anxiety disorder percentage as shown in Table 5.

\section{Correlations between the severity of IBD and the severity} of depression and anxiety disorders

We found neither correlation between the total score of HAM-D and the total Mayo score for UC or the CDAI score for Crohn's disease, nor a correlation between the total score of HAM-A and the total Mayo score for UC or the CDAI score for Crohn's disease as illustrated in Table 6.

\section{Different types of treatment received by the patients are demonstrated in Table 7 \\ Relation between different types of treatment received by the patients and the presence of depression and anxiety} We found no significant relation between different types of treatment and the presence of major depressive disorder (Table 8).

As regards generalized anxiety disorder, we found only significant relation between azathioprine treatment and the presence of generalized anxiety disorder as we found

Table 2 The prevalence of major depressive disorder and generalized anxiety disorder

\begin{tabular}{|c|c|c|c|c|c|}
\hline & & Mean/N & $S D / \%$ & Median (IQR) & Range \\
\hline \multirow[t]{2}{*}{ Major depressive disorder } & No & 46 & $43.8 \%$ & & \\
\hline & Yes & 59 & $56.2 \%$ & & \\
\hline \multirow[t]{2}{*}{ Generalized anxiety disorder } & No & 66 & $62.9 \%$ & & \\
\hline & Yes & 39 & $37.1 \%$ & & \\
\hline Hamilton Depression Score $(N=59)$ & & 16.4 & 5.8 & $14(12-22)$ & $(8-29)$ \\
\hline Hamilton Anxiety Score $(N=39)$ & & 19.5 & 9.5 & $17(13-22)$ & $(10-50)$ \\
\hline
\end{tabular}

IQR interquartile range; SD standard deviation 
Table 3 Comorbidity between major depressive disorder and generalized anxiety disorder

\begin{tabular}{|c|c|c|c|c|c|c|}
\hline & & \multicolumn{2}{|c|}{ Major depressive disorder } & \multicolumn{3}{|c|}{ Chi-square test } \\
\hline & & \multirow{2}{*}{$\begin{array}{l}\text { No }(N=46) \\
N(\%) \\
\text { Mean } \pm S D\end{array}$} & \multirow{2}{*}{$\begin{array}{l}\text { Yes }(N=59) \\
N(\%) \\
\text { Mean } \pm S D\end{array}$} & & & \\
\hline & & & & $x^{2}$ & $p$-value & Sig. \\
\hline \multirow[t]{2}{*}{ Generalized anxiety disorder } & No & $46(100 \%)$ & $20(33.9 \%)$ & 48.374 & $<0.001^{\mathrm{a}}$ & $S$ \\
\hline & Yes & $0(0 \%)$ & $39(66.1 \%)$ & & & \\
\hline Hamilton Depression Score & & & $16.41 \pm 5.8$ & & & \\
\hline Hamilton Anxiety Score & & & 19.499 .53 & & & \\
\hline
\end{tabular}

${ }^{a}$ Chi-square test of significance; $X^{2}$, chi-square test value

a high prevalence of anxiety in patients receiving azathioprine treatment $(p$-value $=0.032)$ (Table 9).

\section{Discussion}

A close relationship and two-way communication are present between the brain and the gut, occurring continuously through the brain-gut axis (BGA). BGA is an indirect communication and offers a biological construct to support the biopsychosocial concept of gastrointestinal diseases [17]. Psychiatric disorders often occur in gastrointestinal diseases and vice versa [18].

Many reported works have recently studied the connection between IBD and psychological disorders $[19,20]$ and have compared the extent of anxiety and depression between subtypes of IBD [21, 22]. Nevertheless, the IBD relationship with psychiatric illness (depression or anxiety) exhibited inconsistency even in a recently reported meta-analysis with eight studies [23]. The results' heterogeneity was too high without subsequent analysis of the reason.

IBD is a chronic disorder that makes its patients more likely to experience anxiety than the overall population [24]. Depression and anxiety are much more frequent than expected in IBD patients, especially those with CD. UC patients are also more likely to experience anxiety disorders than the general population or patients who are suffering from other chronic disease types [25].

Our study revealed a high depression prevalence $(56.2 \%)$ and a high anxiety prevalence $(37.1 \%)$ in our sample. Our findings match those of patients with long-term health problems that generally have an increased risk of

Table 4 Multivariable logistic regression analysis of the relationship between patient demographic and disease characteristics and the existence of major depressive disorder

\begin{tabular}{|c|c|c|c|c|c|c|c|}
\hline & & \multicolumn{2}{|c|}{ Major depressive disorder } & \multirow[t]{3}{*}{ OR (Cl 95\%) } & \multicolumn{3}{|c|}{ Test of significance } \\
\hline & & \multirow{2}{*}{$\begin{array}{l}\text { No }(N=46) \\
\text { Mean } \pm S D \\
\mathrm{~N}(\%)\end{array}$} & \multirow{2}{*}{$\begin{array}{l}\text { Yes }(N=59) \\
\text { Mean } \pm S D \\
\mathrm{~N}(\%)\end{array}$} & & & & \\
\hline & & & & & Value & $p$-value & Sig. \\
\hline Age & & $30.61 \pm 8.72$ & $35.19 \pm 12.2$ & & $\boldsymbol{t}=-2.152$ & $0.034^{\top}$ & S \\
\hline \multirow[t]{2}{*}{ Sex } & Female & $21(45.65 \%)$ & $35(59.32 \%)$ & $0.58(0.26-1.26)$ & $x^{2}=1.941$ & $0.164^{c}$ & NS \\
\hline & Male & $25(54.35 \%)$ & $24(40.68 \%)$ & & & & \\
\hline \multirow[t]{2}{*}{ Residency } & Urban & $34(73.91 \%)$ & $43(72.88 \%)$ & $1.05(0.44-2.53)$ & $X^{2}=0.014$ & $0.906^{C}$ & NS \\
\hline & Rural & $12(26.09 \%)$ & $16(27.12 \%)$ & & & & \\
\hline \multirow[t]{3}{*}{ Marital status } & Single & $26(56.52 \%)$ & $27(45.76 \%)$ & Ref. & & $0.565^{\mathrm{F}}$ & NS \\
\hline & Married & $19(41.3 \%)$ & $29(49.15 \%)$ & $1.5(0.68-3.32)$ & & & \\
\hline & Divorced & $1(2.17 \%)$ & $3(5.08 \%)$ & $2.53(0.24-26.6)$ & & & \\
\hline \multirow[t]{2}{*}{ IBD } & UC & $37(80.43 \%)$ & $45(76.27 \%)$ & $1.28(0.5-3.29)$ & $x^{2}=0.262$ & $0.609^{c}$ & NS \\
\hline & Crohn's & $9(19.57 \%)$ & $14(23.73 \%)$ & & & & \\
\hline Mayo Score UC $(N=37,45)$ & & $8.03 \pm 2.48$ & $8.69 \pm 2.64$ & & $\boldsymbol{t}=-1.162$ & $0.249^{\top}$ & NS \\
\hline $\operatorname{CDAI}(N=9,14)$ & & $238.93 \pm 78.56$ & $238.79 \pm 52.62$ & & $t=0.005$ & $0.996^{\top}$ & NS \\
\hline
\end{tabular}

T Student $t$-test of significance; $t$, Student $t$-test value

${ }^{C}$ Chi-square test of significance; $X^{2}$, chi-square test value

${ }^{F}$ Monte-Carlo Fisher's exact test of significance 
Table 5 Multivariate logistic regression analysis of the relationship between demographic and pathological characteristics of patients and existence of generalized anxiety disorder

\begin{tabular}{|c|c|c|c|c|c|c|c|}
\hline & & \multicolumn{2}{|c|}{ Generalized anxiety disorder } & \multirow[t]{3}{*}{ OR (Cl 95\%) } & \multicolumn{3}{|c|}{ Test of significance } \\
\hline & & \multirow{2}{*}{$\begin{array}{l}\text { No }(N=66) \\
\text { Mean } \pm S D \\
\mathrm{~N}(\%)\end{array}$} & \multirow{2}{*}{$\begin{array}{l}\text { Yes }(N=39) \\
\text { Mean } \pm S D \\
\mathrm{~N}(\%)\end{array}$} & & & & \\
\hline & & & & & Value & $p$-value & Sig. \\
\hline Age & & $32.89 \pm 11.42$ & $33.67 \pm 10.39$ & & $\boldsymbol{t}=-0.346$ & $0.730^{\top}$ & NS \\
\hline \multirow[t]{2}{*}{ Sex } & Female & $31(46.97 \%)$ & $25(64.1 \%)$ & $0.5(0.22-1.12)$ & $x^{2}=2.891$ & $0.089^{C}$ & NS \\
\hline & Male & $35(53.03 \%)$ & $14(35.9 \%)$ & & & & \\
\hline \multirow[t]{2}{*}{ Residency } & Urban & $47(71.21 \%)$ & $30(76.92 \%)$ & $0.74(0.3-1.85)$ & $x^{2}=0.409$ & $0.523^{C}$ & NS \\
\hline & Rural & $19(28.79 \%)$ & $9(23.08 \%)$ & & & & \\
\hline \multirow[t]{3}{*}{ Marital status } & Single & $34(51.52 \%)$ & $19(48.72 \%)$ & Ref. & & $0.826^{F}$ & NS \\
\hline & Married & $30(45.45 \%)$ & $18(46.15 \%)$ & $1.11(0.49-2.54)$ & & & \\
\hline & Divorced & $2(3.03 \%)$ & $2(5.13 \%)$ & $1.33(0.17-10.7)$ & & & \\
\hline \multirow[t]{2}{*}{ IBD } & UC & $52(78.79 \%)$ & $30(76.92 \%)$ & $1.11(0.43-2.88)$ & $X^{2}=0.05$ & $0.823^{C}$ & NS \\
\hline & Crohn's & $14(21.21 \%)$ & $9(23.08 \%)$ & & & & \\
\hline Mayo score UC $(N=52,30)$ & & $8.19 \pm 2.48$ & $8.73 \pm 2.73$ & & $\boldsymbol{t}=-0.917$ & $0.362^{\top}$ & NS \\
\hline $\operatorname{CDAI}(N=14,9)$ & & $246.53 \pm 71.71$ & $226.89 \pm 45.3$ & & $\boldsymbol{t}=0.730$ & $0.473^{\top}$ & NS \\
\hline
\end{tabular}

T Student $t$-test of significance; $t$, Student $t$-test value

${ }^{C}$ Chi-square test of significance; $X^{2}$, chi-square test value

${ }^{F}$ Monte-Carlo Fisher's exact test of significance

major depression [26]. The results were also consistent with other works, indicating that anxiety and depression prevalence in IBD patients exhibited a high level compared to the control group [27].

Byrne et al. noticed that the prevalence of anxiety and depression in patients with IBD $(21.2 \%$ and $25.8 \%$, respectively) is over that of the general Canadian population. Besides, Thomson and Sulman found more than $25 \%$ of people with IBD experienced depression at some point in their lives, while anxiety can affect more than $30 \%$ [28].

In patients with IBD, the anxiety rate during remission periods has been estimated to be 29 to $35 \%$ and in relapses up to $80 \%$ [29]. A Dutch study of 231 patients suffering from IBD found that up to $43 \%$ exhibited a higher anxiety level, indicating a psychiatric disorder, and those anxiety symptoms, in addition to psychiatric complaints, are not adequately treated [30].
The rate of differences in depression and anxiety presented in various studies is possible because of variation in the populations under study and the employed methods for depression and anxiety assessment, in addition to the period during which both depression and/or anxiety were evaluated [31].

Regarding the socio-demographic characteristics, we found a significant association between depression and age since depression was more common in older patients, while we did not find differences in terms of sex or marital status.

Like our results, older age was speculated as a risk factor. In a study of Korean origin inactive IBD patients with mood disorders, 40 years of age or older was regarded as an independent indicator of the low life quality [32].

The gender of females as a risk factor in patients with IBD for psychological disorders is controversial. Similar

Table 6 Correlation between the total score of HAM-D and HAM-A with Mayo score of UC and CDAI score of Crohn's disease

\begin{tabular}{llll}
\hline & & Mayo score UC $(\boldsymbol{N}=\mathbf{4 5})$ & CDAI $(\boldsymbol{N}=\mathbf{1 4})$ \\
\hline Hamilton Depression Score & Pearson correlation & 0.131 & 0.130 \\
& -value & 0.393 & 0.657 \\
& Sig. & NS & NS \\
Hamilton Anxiety Score & & Mayo score UC $(\boldsymbol{N}=\mathbf{3 0})$ & $\mathbf{C D A l}(\boldsymbol{N}=\mathbf{9})$ \\
& Pearson correlation & -0.038 & 0.287 \\
& p-value & 0.841 & 0.455 \\
& Sig. & NS & NS \\
\hline
\end{tabular}


Table 7 Different types of treatment received by patients

\begin{tabular}{llll}
\hline Type of treatment & & $\boldsymbol{N}$ & $\%$ \\
\hline Oral mesalamine & No & 31 & $29.5 \%$ \\
Topical mesalamine & Yes & 74 & $70.5 \%$ \\
& No & 101 & $96.2 \%$ \\
Oral steroids & Yes & 4 & $3.8 \%$ \\
Topical steroids & Yes & 69 & $65.7 \%$ \\
& No & 36 & $34.3 \%$ \\
Azathioprine & Yes & 2 & $98.1 \%$ \\
& No & 35 & $1.9 \%$ \\
Biological therapy & Yes & 70 & $33.3 \%$ \\
Surgical intervention & No & 84 & $66.7 \%$ \\
& Yes & 21 & $80.0 \%$ \\
& No & 98 & $20.0 \%$ \\
& Yes & 7 & $93.3 \%$ \\
\hline
\end{tabular}

to our results, Nahon et al. found no female predominance in anxious IBD patients [29]. In contrast to our results, females were linked to increased anxiety risk, as reported in various studies of IBD patients and the general population [33]. Female patients are also more prone to depression in several studies $[27,33]$.
In terms of anxiety and depression prevalence, we found no distinction among UC and CD patients, which agrees with previous studies [34]. On the contrary, Neuendorf et al. found disease type impact with a higher prevalence rate of depressive symptoms in patients with CD than in patients with UC [35].

There was no correlation between both the severity of depression and anxiety and the severity of IBD, either ulcerative colitis or Crohn's disease. Although we have not found any studies that directly correlate the severity of psychiatric disorders and IBD, we found indirect relationships that reflect the negative effect of IBD severity on anxiety or depression severity. For instance, Nahon et al. and Häuser et al. noticed that IBD activity exhibited a significant association with an increased risk for depression and anxiety in IBD patients $[29,36]$.

IBD activity is also strongly related to psychological symptoms, as more anxiety symptoms were also seen in flaring periods of patients with IBD [28]. A study in patients with UC stated that endoscopically confirmed active mucosal inflammation was linked to increased psychological stress [37]. Indirectly, patients requiring immunomodulatory and biological therapy for IBD treatment were also at augmented risk of comorbid anxiety and depression associated with the severity of IBD disease [38].

Table 8 Multivariable logistic regression analysis of the relationship between treatment types received by the patient and major depressive disorder

\begin{tabular}{|c|c|c|c|c|c|c|c|}
\hline & & \multicolumn{2}{|c|}{ Major depressive disorder } & \multirow[t]{3}{*}{ OR (Cl 95\%) } & \multicolumn{3}{|c|}{ Test of significance } \\
\hline & & \multirow{2}{*}{$\begin{array}{l}\text { No }(N=46) \\
N(\%)\end{array}$} & \multirow{2}{*}{$\begin{array}{l}\text { Yes }(N=59) \\
N(\%)\end{array}$} & & & & \\
\hline & & & & & Value & $p$-value & Sig. \\
\hline \multirow[t]{2}{*}{ Oral mesalamine } & No & $14(30.43 \%)$ & $17(28.81 \%)$ & $1.08(0.47-2.51)$ & $X^{2}=0.033$ & $0.857^{C}$ & NS \\
\hline & Yes & $32(69.57 \%)$ & $42(71.19 \%)$ & & & & \\
\hline \multirow[t]{2}{*}{ Topical mesalamine } & No & $44(95.65 \%)$ & $57(96.61 \%)$ & $0.77(0.11-5.7)$ & & $1.00^{\mathrm{F}}$ & NS \\
\hline & Yes & $2(4.35 \%)$ & $2(3.39 \%)$ & & & & \\
\hline \multirow[t]{2}{*}{ Oral steroids } & No & $28(60.87 \%)$ & $41(69.49 \%)$ & $0.68(0.3-1.54)$ & $X^{2}=0.853$ & $0.356^{c}$ & NS \\
\hline & Yes & $18(39.13 \%)$ & $18(30.51 \%)$ & & & & \\
\hline \multirow[t]{2}{*}{ Topical steroids } & No & $44(95.65 \%)$ & $59(100 \%)$ & & & $0.19^{\mathrm{F}}$ & NS \\
\hline & Yes & $2(4.35 \%)$ & $0(0 \%)$ & & & & \\
\hline \multirow[t]{2}{*}{ Azathioprine } & No & $16(34.78 \%)$ & $19(32.2 \%)$ & $1.12(0.5-2.54)$ & $x^{2}=0.077$ & $0.781^{c}$ & NS \\
\hline & Yes & $30(65.22 \%)$ & $40(67.8 \%)$ & & & & \\
\hline \multirow[t]{2}{*}{ Biological therapy } & No & $37(80.43 \%)$ & $47(79.66 \%)$ & $1.05(0.4-2.76)$ & $X^{2}=0.01$ & $0.922^{C}$ & NS \\
\hline & Yes & $9(19.57 \%)$ & $12(20.34 \%)$ & & & & \\
\hline \multirow[t]{2}{*}{ Type remicade 1-Humera 2} & No & $40(86.96 \%)$ & $51(86.44 \%)$ & $1.05(0.34-3.26)$ & $x^{2}=0.006$ & $0.939^{c}$ & NS \\
\hline & Yes & $6(13.04 \%)$ & $8(13.56 \%)$ & & & & \\
\hline \multirow[t]{2}{*}{ Surgical intervention } & No & $43(93.48 \%)$ & $55(93.22 \%)$ & $1.04(0.22-4.91)$ & & $1.00^{\mathrm{F}}$ & NS \\
\hline & Yes & $3(6.52 \%)$ & $4(6.78 \%)$ & & & & \\
\hline \multirow[t]{2}{*}{ Did you stop TTT? } & No & $40(86.96 \%)$ & $54(91.53 \%)$ & $0.62(0.18-2.17)$ & & $0.529^{F}$ & NS \\
\hline & Yes & $6(13.04 \%)$ & $5(8.47 \%)$ & & & & \\
\hline
\end{tabular}

\footnotetext{
${ }^{C}$ Chi-square test of significance ( $X^{2}$, chi-square test value). ${ }^{\mathrm{F}}$ Monte-Carlo Fisher's exact test of significance
} 
Table 9 Multivariate logistic regression analysis of the relationship between treatments received by the patient and generalized anxiety disorder

\begin{tabular}{|c|c|c|c|c|c|c|c|}
\hline & & \multicolumn{2}{|c|}{ Generalized anxiety disorder } & \multirow[t]{3}{*}{ OR (Cl 95\%) } & \multicolumn{3}{|c|}{ Test of significance } \\
\hline & & \multirow{2}{*}{$\begin{array}{l}\text { No }(N=66) \\
N(\%)\end{array}$} & \multirow{2}{*}{$\begin{array}{l}\text { Yes }(N=39) \\
N(\%)\end{array}$} & & & & \\
\hline & & & & & Value & $p$-value & Sig. \\
\hline \multirow[t]{2}{*}{ Oral mesalamine } & No & $18(27.27 \%)$ & $13(33.33 \%)$ & $0.75(0.32-1.77)$ & $x^{2}=0.433$ & $0.511^{c}$ & NS \\
\hline & Yes & $48(72.73 \%)$ & $26(66.67 \%)$ & & & & \\
\hline \multirow[t]{2}{*}{ Topical mesalamine } & No & $63(95.45 \%)$ & $38(97.44 \%)$ & $0.55(0.06-5.51)$ & & $1.00^{\mathrm{F}}$ & NS \\
\hline & Yes & $3(4.55 \%)$ & $1(2.56 \%)$ & & & & \\
\hline \multirow[t]{2}{*}{ Oral steroids } & No & $43(65.15 \%)$ & $26(66.67 \%)$ & $0.94(0.41-2.16)$ & $X^{2}=0.025$ & $0.874^{c}$ & NS \\
\hline & Yes & $23(34.85 \%)$ & $13(33.33 \%)$ & & & & \\
\hline \multirow[t]{2}{*}{ Topical steroids } & No & $64(96.97 \%)$ & $39(100 \%)$ & & & $0.529^{\mathrm{F}}$ & NS \\
\hline & Yes & $2(3.03 \%)$ & $0(0 \%)$ & & & & \\
\hline \multirow[t]{2}{*}{ Azathioprine } & No & $27(40.91 \%)$ & $8(20.51 \%)$ & $2.68(1.07-6.73)$ & $X^{2}=4.589$ & $0.032^{c}$ & $S$ \\
\hline & Yes & $39(59.09 \%)$ & $31(79.49 \%)$ & & & & \\
\hline \multirow[t]{2}{*}{ Biological therapy } & No & $55(83.33 \%)$ & $29(74.36 \%)$ & $1.72(0.66-4.54)$ & $x^{2}=1.234$ & $0.267^{c}$ & NS \\
\hline & Yes & $11(16.67 \%)$ & $10(25.64 \%)$ & & & & \\
\hline \multirow[t]{2}{*}{ Type remicade 1-Humera 2} & No & $59(89.39 \%)$ & $32(82.05 \%)$ & $1.84(0.59-5.72)$ & $X^{2}=1.144$ & $0.285^{C}$ & NS \\
\hline & Yes & $7(10.61 \%)$ & $7(17.95 \%)$ & & & & \\
\hline \multirow[t]{2}{*}{ Surgical intervention } & No & $61(92.42 \%)$ & 37 (94.87\%) & $0.66(0.12-3.57)$ & & $1.00^{\mathrm{F}}$ & NS \\
\hline & Yes & $5(7.58 \%)$ & $2(5.13 \%)$ & & & & \\
\hline
\end{tabular}

${ }^{c}$ Chi-square test of significance ( $X^{2}$, chi-square test value). ${ }^{\mathrm{F}}$ Monte-Carlo Fisher's exact test of significance

Psychiatric comorbidities can be successfully treated in chronic inflammatory diseases [39], and this may provide improved results in individuals with IBD. Until now, depression and anxiety disorders in people with IBD are not recognized and are not adequately treated. One study estimated that of $43 \%$ of people with depression or anxiety symptoms, only $18 \%$ received psychological treatment and $21 \%$ took psychotropic drugs [30].

Anxiety and depression were considered to have a direct impact on health-related quality of life (HRQOL) in people with IBD, regardless of disease activity [40]. Zhang et al. investigated depression and disease severity role as individual factors to predict the life quality [41]. Besides, psychiatric disorders of patients with IBD can anticipate costly results, comprising emergency room visits and IBD-related hospitalizations, in addition to high treatment costs [42]. The possible advantages of treatment for mental health, as well as a higher prevalence of depression and anxiety in IBD patients, suggest that screening for depression and anxiety in such a population may be helpful. The brain-gut axis pathophysiology may hold a significant function in IBD, in addition to inflammation and psychological symptoms. TNF-alpha, a pro-inflammatory cytokine, was defined as a key factor. Additional efforts in such areas could showcase future therapeutic targets towards IBD and improve psychological symptoms [43].

As identified herein, the high prevalence of mental disorders represents a major issue, requiring particular concern. Since psychiatric disorders have a significant impact on disease progression, relapse rates, treatment outcomes, and life quality, it is important to foster collaboration between gastroenterologists and psychiatrists. Detection of psychiatric disorders in patients with $C D$ and $U C$ should be part of the medical approach to IBD. Achievement of psychological remission and remission of somatic symptoms appears to be a promising result in IBD treatment [44].

\section{Conclusions}

The prevalence of depression and anxiety in patients with chronic diseases in the general population is high. The patients continue to receive insufficient treatment despite their significant adverse influences on the health and life quality of patients. Our study demonstrated that more than half of IBD patients suffered from major depressive disorder, generalized anxiety disorder, or both. This high prevalence of depression and/or anxiety warrants psychiatric screening and referral in clinics that serve this population. Clinicians should be aware that these psychiatric disorders can occur as a result of IBD. Consequently, a collaborative approach is required to ensure therapy optimization for IBD patients. 


\section{Abbreviations}

BGA: Brain-gut axis; CD: Crohn's disease; CDAl: Crohn's Disease Activity Index; DSM IV: Diagnostic and Statistical Manual IV; HAM-A: Hamilton Scale for Anxiety; HAM-D: Hamilton Scale for Depression; HR-QOL: Health-related quality of life; IBD: Inflammatory bowel disease; IQR: Interquartile range; SCID I: Structured Clinical Interview for DSM IV axis I disorders; SPSS: Statistical Package for the Social Science; UC: Ulcerative colitis.

\section{Acknowledgements}

"Not applicable".

\section{Authors' contributions}

S.A, H. R, and O. A. designed the research; S. A, M. E., W.A., and O. A. performed the research; M. A. and S. K. contributed analytic tools; M. A. and A. F. analyzed the data; S. A. and O. A. wrote the paper. All authors read and approved the final manuscript.

\section{Funding}

This research did not receive any specific grant from funding agencies in the public, commercial, or not-for-profit sectors.

\section{Availability of data and materials}

The data underlying this article will be shared on reasonable request to the corresponding author.

\section{Declarations}

\section{Ethics approval and consent to participate}

The nature of the study was discussed with each patient, and written informed consent was obtained from all parents before participating in the study. This study was approved by Ain Shams University Hospital Ethics Committee after a very clear statement that provided information on the following points: study rationale; participation in this study was completely free and voluntary; participation in the study had no direct benefit to him, although the data obtained could be used for the benefit of other patients; they may be withdrawn at any time without giving any justification and without affecting their care service; and the results of the study may be used for scientific publication but the identities of the patients would be completely secret.

The committee's reference number is R 107/ 2021.

\section{Consent for publication}

"Not applicable".

\section{Competing interests}

The authors declare that they have no competing interests.

\section{Author details}

${ }^{1}$ Department of Tropical Medicine, Faculty of Medicine, Ain Shams University, Abbasiya square, Cairo 11566, Egypt. ${ }^{2}$ Department of Psychiatry, Faculty of Medicine, Ain Shams University, Abbasiya square, Cairo 11566, Egypt. ${ }^{3}$ Department of Psychiatry, Faculty of Medicine, Ain Shams University, No. 38 Abbaseya st., Cairo 11517, Egypt.

Received: 10 July 2021 Accepted: 13 October 2021

Published online: 07 December 2021

\section{References}

1. Azzam NA, Aljebreen A, Almuhareb A, Almadi MA (2020) Disability and quality of life before and during the COVID-19 outbreak: a cross-sectional study in inflammatory bowel disease patients. Saudi J Gastroenterol 26:256-262

2. Clarke DM, Currie KC (2009) Depression, anxiety and their relationship with chronic diseases: a review of the epidemiology, risk and treatment evidence. Med. J. Aust 190(7):S54-S60
3. Katon W J (2011). "Epidemiology and treatment of depression in patients with chronic medical illness," Dialogues Clin. Neurosci; vol. 13, no. 1, pp. 7-23

4. Bannaga AS, Selinger CP (2015) Inflammatory bowel disease and anxiety: links, risks, and challenges faced. Clin Exp Gastroenterol 8:111-117

5. Marrie RA, Walker JR, Gra LA et al (2016) Performance of administrative case definitions for depression and anxiety in inflammatory bowel disease. J Psychosom Res 89:107-113

6. Walus MA, Pittet V, Rossel JB, von Kanel R (2016) Swiss IBD cohort stud group. Symptoms of depression and anxiety are independently associated with clinical recurrence of inflammatory bowel disease. Clin Gastroentero Hepatol 14(6):829-835

7. Bernstein CN (2016) Psychological stress and depression: risk factors for IBD? Di Dis 34(1-2):58-63

8. Gracie DJ, Guthrie EA, Hamlin PJ, Ford AC (2018) Bi-directionality of braingut interactions in patients with inflammatory bowel disease. Gastroenterology 154(6):1635-1646 e3

9. Berk M, Williams $L$, Jacka FN et al (2013) So depression is an inflammatory disease, but where does the inflammation come from? BMC Med $11: 200$

10. First MB, Spitzer RL, Gibbon M, Williams JBW (2002) SCID I clinician version. D.C. American Psychiatric Press, Washington

11. Magro F et al (2017) Third European evidence-based consensus on diagnosis and management of ulcerative colitis. Part 1: definitions, diagnosis, extra-intestinal manifestations, pregnancy, cancer surveillance, surgery, and ileo-anal pouch disorders. J Crohn's Colitis 11(6):649-670

12. El-Missiry A., Sorour A., Sadek A. et al (2004): Homicide and psychiatric illness: an Egyptian study. M.D. Thesis. Faculty of medicine. Ain Shams University

13. Hamilton M (1960) A rating scale for depression. J Neurol Neurosurg Psychiatry 23:56-62

14. Hamilton M (1959) The assessment of anxiety states by rating. Br J Med Psychol 32:50-55

15. Thia K, Faubion WA Jr, Loftus EV Jr, Persson T, Persson A, Sandborn WJ (2011) Short CDAl: development and validation of a shortened and simplified Crohn's disease activity index. Inflamm Bowel Dis 17(1):105-111

16. Bewtra M, Brensinger CM, Tomov VT, Hoang TB, Sokach CE, Siegel CA, Lewis JD (2014) An optimized patient-reported ulcerative colitis disease activity measure derived from the Mayo score and the simple clinical colitis activity index. Inflamm Bowel Dis 20(6):1070-1078

17. Sadock BJ, Sadock VA, Ruiz P (2017) Kaplan \& Sadock's comprehensive textbook of psychiatry, 10th edn. Wolters Kluver, Philadelphia, pp 2200-2210

18. Zhao D, Wu Z, Zhang H et al (2018) Somatic symptoms vary in major depressive disorder in China. Compr Psychiatry 87:32-37

19. [15]-Komuro H, Sato N, Sasaki A, et al. (2016). Corticotropin-releasing hormone receptor 2 gene variants in irritable bowel syndrome. PLoS One; 11: e0147817

20. Sasaki A, Sato N, Suzuki N et al (2016) Associations between single-nucleotide polymorphisms in corticotropin-releasing hormone-related genes and irritable bowel syndrome. PLoS One 11(2):e0149322

21. Thijssen AY, Mujagic Z, Jonkers DM et al (2016) Alterations in serotonin metabolism in the irritable bowel syndrome. Aliment Pharmacol Ther 43:272-282

22. Jones MP, Chey WD, Singh S et al (2014) A biomarker panel and psychological morbidity differentiates the irritable bowel syndrome from health and provides novel pathophysiological leads. Aliment Pharmacol Ther 39:426-437

23. Fond G, Loundou A, Hamdani N et al (2014) Anxiety and depression comorbidities in irritable bowel syndrome (IBS): a systematic review and meta-analysis. Eur Arch Psychiatry Clin Neurosci 264:651-660

24. Scott K, Bruffaerts R, Tsang A et al (2007) Depression-anxiety relationships with chronic physical conditions: results from the world mental health surveys. J Affect Disord 103:113-120

25. Magni G, Bernasconi G, Mauro P et al (1991) Psychiatric diagnoses in ulcerative colitis. A controlled study. Br J Psychiatry 158:413-415

26. Patten B (2001) Long-term medical conditions and major depression in a Canadian population study at waves 1 and 2. J Affect Disord 63(1-3):35-41 
27. Goodhand JR, Wahed M, Mawdsley JE et al (2012) Mood disorders in inflammatory bowel disease: relation to diagnosis, disease activity, perceived stress, and other factors. Inflamm Bowel Dis 18(12):2301-2309

28. Byrne G, Rosenfeld G, Leung Y et al. (2018). Prevalence of anxiety and depression in patients with inflammatory bowel disease

29. Thomson EF, Sulman J (2006) Depression and inflammatory bowel disease: findings from two nationally representative Canadian surveys. Inflamm Bowel Dis 12(8):697-707

30. Nahon S, Lahmek P, Durance C et al (2012) Risk factors of anxiety and depression in inflammatory bowel disease. Inflamm Bowel Dis 18(11):2086-2091

31. Bennebroek EF, Thijssens N, Stokkers P et al (2012) Do inflammatory bowel disease patients with anxiety and depressive symptoms receive the care they need? J Crohns Colitis 6:68-76

32. Kim E, Cho K, Park K et al (2013) Predictive factors of impaired quality of life in Korean patients with inactive inflammatory bowel disease: association with functional gastrointestinal disorders and mood disorders. J Clin Gastroenterol 47:38-44

33. Pearson C, Janz T, Ali J (2013) Health at a glance mental and substance use disorders in Canada. Stat Canada 82:1-8

34. Trachter A, Rogers A, Leiblum S (2002) Inflammatory bowel disease in women: impact on the relationship and sexual health. Inflamm Bowel Dis 8:413-421

35. Neuendorf R, Harding A, Stello N, Hanes D, Wahbeh H (2016) (2016), Depression and anxiety in patients with inflammatory bowel disease: a systematic review. J Psychosom Res 87:70-80

36. Häuser W, Janke KH, Klump B, Hinz A (2011) Anxiety and depression in patients with inflammatory bowel disease: comparisons with chronic liver disease patients and the general population. Inflamm Bowel Dis 17(2):621-632
37. Bernstein C, Singh S, Graff L et al (2010) A prospective population based study of triggers of symptomatic flares in IBD. Am J Gastroenterol 105:1994-2002

38. Navabi S, Gorrepati VS, Yadav S et al (2018) Influences and impact of anxiety and depression in the setting of inflammatory bowel disease. Inflamm. Bowel Dis 24:2303-2308

39. Fiest KM, Walker JR, Bernstein CN et al (2016) Systematic review and meta-analysis of interventions for depression and anxiety in persons with multiple sclerosis. Mult Scler Relat Disord 5:12-26

40. Guthrie E, Jackson J, Shaffer J et al (2002) Psychological disorder and severity of inflammatory bowel disease predict health-related quality of life in ulcerative colitis and Crohn's disease. Am J Gastroenterol 97(8):2-7

41. Zhang CK, Hewett J, Hemming J et al (2013) The influence of depression on quality of life in patients with inflammatory bowel disease. Inflamm Bowel Dis 19(8):1732-1739

42. Limsrivilai J, Stidham R W, Govani S M et al. (2017). Higgins, "Factors that predict high health care utilization and costs for patients with inflammatory bowel diseases," Clin Gastroenterol Hepatol; vol. 15, no. 3, pp. 385-392

43. Bonaz B, Bemestein C (2013) Brain-gut interactions in inflammatory bowel disease. Gastroenterology 144:36-49

44. Acosta BM, Gisbert JP (2014) Letter: psychological remission - a future endpoint in inflammatory bowel disease? Aliment Pharmacol Ther 39(12):1436-1436

\section{Publisher's Note}

Springer Nature remains neutral with regard to jurisdictional claims in published maps and institutional affiliations.

\section{Submit your manuscript to a SpringerOpen ${ }^{\circ}$ journal and benefit from:}

- Convenient online submission

- Rigorous peer review

- Open access: articles freely available online

- High visibility within the field

- Retaining the copyright to your article

Submit your next manuscript at $\boldsymbol{\nabla}$ springeropen.com 